\title{
Spatiotemporal dynamics of snow cover based on multi-source remote sensing data in China
}

\author{
Xiaodong Huang ${ }^{1}$, Jie Deng ${ }^{1}$, Xiaofang Ma ${ }^{1}$, Yunlong Wang ${ }^{1}$, Qisheng Feng ${ }^{1}$, Xiaohua Hao ${ }^{2}$, and Tiangang Liang ${ }^{1}$ \\ ${ }^{1}$ Key Laboratory of Grassland Agro-Ecology System, College of Pastoral Agriculture Science and Technology, \\ Lanzhou University, 730020 Lanzhou, China \\ ${ }^{2}$ Chinese Academy of Sciences, Cold and Arid Regions Environmental and Engineering Research Institute, \\ 730000 Lanzhou, China
}

Correspondence to: Xiaodong Huang (huangxd@1zu.edu.cn)

Received: 19 May 2016 - Published in The Cryosphere Discuss.: 16 June 2016

Revised: 19 September 2016 - Accepted: 4 October 2016 - Published: 24 October 2016

\begin{abstract}
By combining optical remote sensing snow cover products with passive microwave remote sensing snow depth (SD) data, we produced a MODIS (Moderate Resolution Imaging Spectroradiometer) cloudless binary snow cover product and a $500 \mathrm{~m}$ snow depth product. The temporal and spatial variations of snow cover from December 2000 to November 2014 in China were analyzed. The results indicate that, over the past 14 years, (1) the mean snow-covered area (SCA) in China was $11.3 \%$ annually and $27 \%$ in the winter season, with the mean SCA decreasing in summer and winter seasons, increasing in spring and fall seasons, and not much change annually; (2) the snow-covered days (SCDs) showed an increase in winter, spring, and fall, and annually, whereas they showed a decrease in summer; (3) the average SD decreased in winter, summer, and fall, while it increased in spring and annually; (4) the spatial distributions of SD and SCD were highly correlated seasonally and annually; and (5) the regional differences in the variation of snow cover in China were significant. Overall, the SCD and SD increased significantly in south and northeast China, and decreased significantly in the north of Xinjiang province. The SCD and SD increased on the southwest edge and in the southeast part of the Tibetan Plateau, whereas it decreased in the north and northwest regions.
\end{abstract}

\section{Introduction}

Snow cover is closely related to human lives, and it has both positive and negative effects (Liang et al., 2004). Highlatitude and midlatitude regions contain abundant snow cover and glacial resources, which are the source regions for many rivers (Zhang et al., 2002). Snowmelt runoff can make up more than $50 \%$ of the total discharge of many drainage basins (Seidel and Martinec, 2004). Snow cover is an important resource for industrial, agricultural, and domestic water use. Especially in arid and semi-arid regions, the development of agricultural irrigation and animal husbandry relies on the melting of snow cover (Pulliainen, 2006; Li, 2001). Winter water deficiencies can easily cause droughts (Kongoli et al., 2012). On the other hand, flood disasters caused by melting snow cover and snow disasters such as avalanches, glacial landslides, and snowdrifts are also common (Gao et al., 2008; Liu et al., 2011; Shen et al., 2013).

Rising temperatures due to global warming rapidly change the snow cover conditions in seasonal snow-covered regions, which has led to accelerated melting of most ice sheets and permanent snow covers (Yao et al., 2012), an increase in snow line elevations (Chen, 2014), a decrease in wetland areas, and the reallocation of precipitation, which has further led to frequent floods and snow disasters (Lee et al., 2013; Wang et al., 2013). Global warming is an indisputable fact, and rising temperature will strongly affect alpine and polar snow cover (IPCC, 2013). The variation of global and regional snow covers greatly affects the use of snow resources by humans, and the feedback mechanism of albedo further 
affects climate (Bloch, 1964; Robinson, 1997; Nolin and Stoeve, 1997). Several studies have indicated that the snow cover in the alpine regions in China affects the atmospheric circulation and weather systems in east Asia and further affects the climate in China (Qian et al., 2003; Zhao et al., 2007). Alpine snow cover has important implications for hydrology, climate, and the ecological environment (Chen and Liu, 2000; Hahn and Shula, 1976).

China is large, and its snow-covered regions are widely distributed geographically. North Xinjiang, northeast ChinaInner Mongolia, and the Tibetan Plateau are the three major regions with seasonal snow cover in China (Wang et al., 2009). They are also the major pasture regions. Winter and spring snowfall is the major water resource in north Xinjiang and the Tibetan Plateau (Pei et al., 2008; Chen et al., 1991; Wang et al., 2014). Heavy snowfall can also cause severe snow disasters and large numbers of livestock deaths (Liu et al., 2008; Chen, 1996). Floods caused by melting snow cover also frequently occur in the spring, severely limiting the development of grassland animal husbandry, and affecting the safety of human lives (Shen et al., 2013). Therefore, accurate acquisition of snow-covered area (SCA) and SD information is significant for understanding climate change and the hydrological cycle, conducting water resource surveys, and preventing and forecasting snow disasters in China.

Recent studies of the distribution and variation of snow cover in China have progressed greatly, but they have mainly focused on the Tibetan Plateau, Xinjiang, and northeast China (Chen and $\mathrm{Li}, 2011$ ). Furthermore, the results from different snow cover datasets are slightly different, and the snow cover variations in different regions are also different. MODIS (Moderate Resolution Imaging Spectroradiometer) data, which have high spatial and temporal resolution, have been widely used in the remote sensing fields of ecology, atmospheric science, and hydrology. However, clouds strongly interfere with optical sensors. Hence, we cannot directly use snow cover products acquired by optical sensors to effectively quantify SCA. Passive microwaves can penetrate clouds and are not affected by weather. However, the coarse resolution of passive microwave products greatly limits the accuracy of regional snow cover monitoring. Therefore, cloud removal and downscaling are effective approaches for enhancing the accuracy of snow cover monitoring using optical and passive microwave products, respectively.

This study used the MODIS daily snow cover product and passive microwave SD data to produce a daily cloudless SCA product and a downscaled SD product with a $500 \mathrm{~m}$ spatial resolution. The integrated daily snow products were used to analyze the temporal and spatial variations of the snow cover in China from December 2000 to November 2014, and quantitatively evaluate the variation of SCA, snow-covered days (SCDs), and average SD to provide a basis for further understanding the interaction between climate and snow cover under the background of global warming in China.

\section{Materials and methods}

\subsection{Study area}

China has a large area and a large population, with mountains, plateaus, and hills accounting for $\sim 67 \%$ of the land area, and basins and plains for $\sim 33 \%$ (Fig. 1). The mountains are mostly oriented east-west and northeast-southwest, including the Altun, Tian Shan, Kunlun, Karakoram, Himalaya, Yin, Qinling, Nanling, Daxing'anling, Changbai, Taihang, Wuyi, Taiwan, and Hengduan. The Tibetan Plateau, which has an average elevation of more than $4000 \mathrm{~m}$, is located to the southwest and is known as the "Roof of the World". Mount Everest is $8844.43 \mathrm{~m}$ in height and is the highest mountain in the world. To the north and east, Inner Mongolia, the Xinjiang area, the Loess Plateau, the Sichuan Basin, and the Yunnan-Guizhou Plateau are second-stage terrains of China. The region from east of the Daxing' anlingTaihang-Wushan-Wuling-Xuefeng Mountains to the shoreline mostly contains third-stage terrains composed of plains and hills, with an average elevation of less than $1000 \mathrm{~m}$. The multi-year stable snow cover is mainly distributed in the Tibetan Plateau, northeast China and Inner Mongolia, and northern Xinjiang, covering a total area of $\sim 4200000 \mathrm{~km}^{2}$. This snow cover forms the major freshwater reservoirs for most parts of China ( $\mathrm{Li}, 1983)$.

\subsection{Remote sensing snow products}

The SD data used in this study were from the "Environmental and Ecological Science Data Center for West China" (http://westdc.westgis.ac.cn), which is a database with a long time series of SD in China (1979-2014) (Che et al., 2008, 2016; Dai et al., 2012, 2015). It is a daily SD database that was inverted using the brightness temperature data of the Scanning Multichannel Radiometer (SMMR) (1978-1987), Special Sensor Microwave/Imager (SSM/I) (1987-2007), and Special Sensor Microwave Imager/Sounder (SSMI/S) (2008-2014) passive microwave remote sensing instruments. This product is saved in text format. The unit of SD is centimeters, and the spatial resolution is $25 \mathrm{~km}$. The database is widely acknowledged and used (Dai et al., 2010; Wang et al., 2013; Bai et al., 2015). The SCA product includes the MOD10A1 and MYD10A1 binary snow cover products of the MODIS/Terra and MODIS/Aqua daily V005 version covering China (Hall et al., 2002). The data were taken from the National Snow and Ice Data Center (NSIDC). The spatial resolution is $500 \mathrm{~m}$, and the time period is from December 2000 to November 2014.

\subsection{Cloud removal and downscaling algorithms}

Following the MODIS cloud removal algorithm developed by Huang et al. (2012), daily cloudless binary snow cover data were produced for December 2000 to November 2014. The cloud removal algorithm can be summarized 


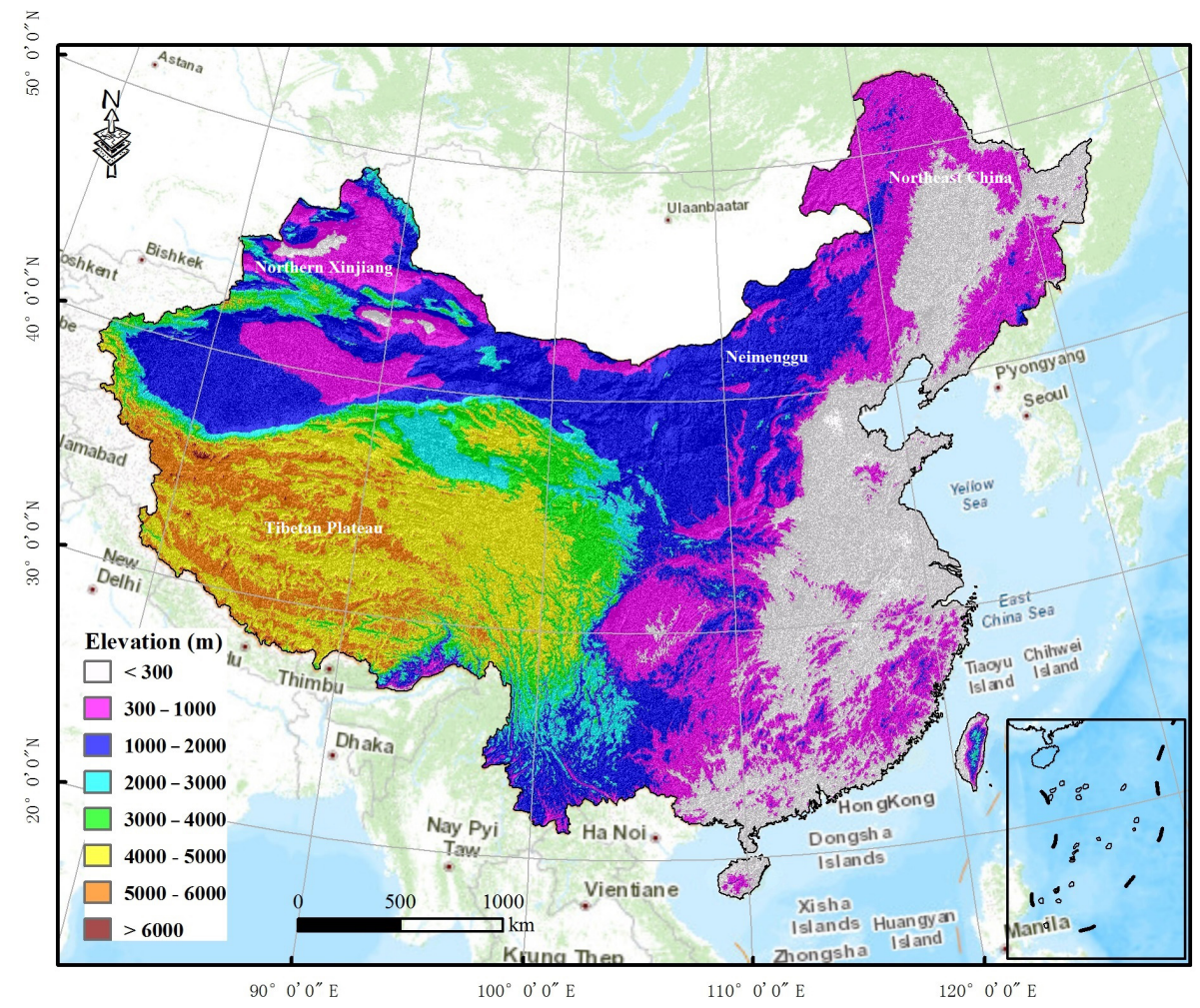

Figure 1. Schematic diagram of the study region.

in three steps. (1) In daily snow cover product synthesis, the MOD10A1 and MYD10A1 snow products were combined using the maximum SCA fusion method in accordance with the different acquisition times of the Terra and Aqua satellites and the characteristics of cloud movement. (2) In adjacent day analysis, the cloud pixels on a given day were replaced with the pixel values on the previous and following days under cloudless conditions. (3) Through a combination with the passive microwave SD product, the long time series SD database of China was used to identify cloud pixels, completely reclassify the residual cloud pixels to land or snow pixels, and produce the MODIS daily cloudless binary snow cover images. Based on the downscaling algorithm for the AMSR-E snow water equivalent product by Mhawej et al. (2014), we applied a downscaling algorithm to the passive microwave SD product and built the $500 \mathrm{~m}$ spatial resolution SD data of China for December 2000 to November 2014. The equation is as follows:

$$
\left\{\begin{array}{l}
\text { if MODIS }=0 \\
\mathrm{SD}_{\mathrm{sp}}=0 \\
\text { else } \\
\mathrm{SD}_{\mathrm{sp}}=\frac{\mathrm{SD} \times \mathrm{SDY}_{i} \times 2500}{\mathrm{SDT}_{i}},
\end{array}\right.
$$

where $\mathrm{SD}_{\mathrm{sp}}$ is the subpixel daily $\mathrm{SD}$ with a $500 \mathrm{~m}$ spatial resolution, $\mathrm{SD}$ is the daily $\mathrm{SD}$ with a $25 \mathrm{~km}$ spatial resolution, $\mathrm{SDY}_{i}$ is the average number of SCDs for each MODIS pixel in year $i$, and $\mathrm{SDT}_{i}$ is the sum of the total SCDs for each $\mathrm{SD}$ pixel in year $i$.

\subsection{Analysis of the snow cover variation}

The Mann-Kendall (M-K) method is a nonparametric test method widely used in the analysis of long time series of data (Helsel and Hirsch, 1992). This method monitors the variation of monotonic nonlinear data. It has no requirement for the data distribution, and it can avoid the interference of a few anomalies (McBean and Motiee, 2008). This study used the $\mathrm{M}-\mathrm{K}$ method to analyze the trend and significance level of the SCDs and SD in China at the pixel scale. For a series $X_{i}=\left(X_{1}, X_{2}, \ldots, X_{n}\right)$ with $n$ samples, the test process is as follows:

$Z=\frac{S}{\sqrt{\operatorname{VAR}(S)}}$,

where

$$
\begin{aligned}
& S=\sum_{i=1}^{n} \sum_{j=i+1}^{n} \operatorname{sgn}\left(X_{j}-X_{i}\right) \\
& \operatorname{sgn}\left(X_{j}-X_{i}\right)= \begin{cases}+1, & \text { if }\left(X_{j}-X_{i}\right)>0 \\
0, & \text { if }\left(X_{j}-X_{i}\right)=0 \\
-1, & \text { if }\left(X_{j}-X_{i}\right)<0\end{cases}
\end{aligned}
$$




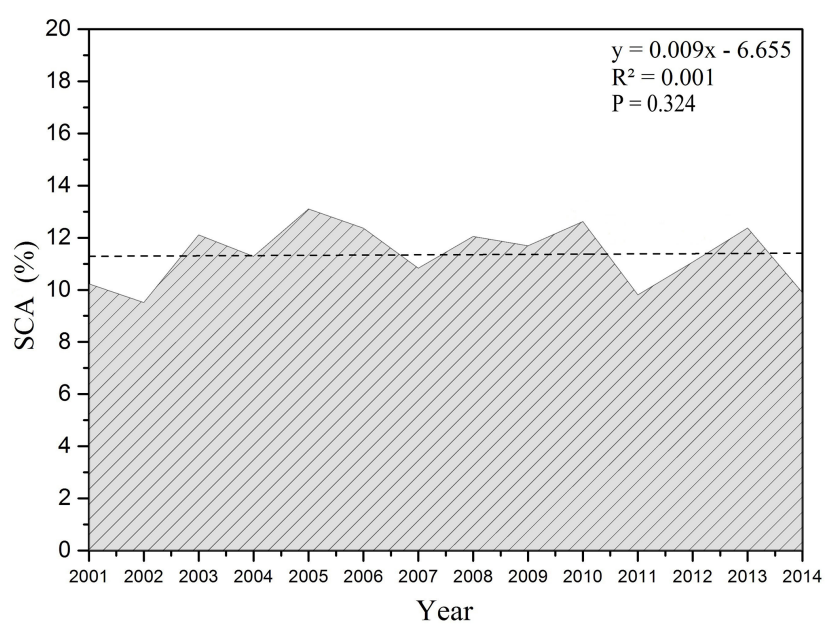

Figure 2. Average annual SCA in China between 2001 and 2014.

$\operatorname{VAR}(S)=\frac{n(n-1)(2 n+5)-\sum_{i=1}^{m} t_{i}\left(t_{i}-1\right)\left(2 t_{i}+5\right)}{18}$,

where $n$ is the year count $(n=14), m$ is the number of nodes (repetitive data groups) in the series, and $t_{i}$ is the node width (the number of repetitive data points in the $i$ th repetitive data group).

When $n \leq 10$, we directly used the statistic $S$ for the twosided trend test. $S>0$ represents an increase, $S=0$ represents no variation, and $S<0$ represents a decrease. At a given significance level $\alpha$, if $|S| \geq S_{\alpha / 2}$, the trend of the series is significant; otherwise, it is insignificant.

When $n>10$, the statistic $S$ approaches the standardized normal distribution. We used the test statistic $Z$ for the twosided trend test. $Z>0$ represents an increase, $Z=0$ represents no variation, and $Z<0$ represents a decrease. At a given significance level $\alpha$, we looked up the critical $Z_{\alpha / 2}$ in the normal distribution table. If $|Z|>Z_{\alpha / 2}$, the series trend is significant; if $|Z| \leq Z_{\alpha / 2}$, the trend is insignificant.

Sen's median method was also used to analyze the slope of the variation in the annual SCDs. This method calculates the median slope of $n(n-1)$ /two pairs of combinations in a series of length $n$. The equation is

$\beta=\operatorname{median}\left(\frac{x_{i}-x_{j}}{i-j}\right), \quad i>j$,

where $\beta>0$ represents an increase in the trend, and $\beta<0$ represents a decrease in the trend.

\section{Results}

\subsection{Snow-covered area}

Figure 2 summarizes the average annual SCA between 2001 and 2014. Leap years occurred in 2004, 2008, and 2012, so the average SCA refers to the mean of 366 days for these years. The results indicate that the average annual SCA in China in 2001-2014 constituted $11.3 \%$ of the entire study region. The average annual SCA varied slightly over the past 14 years, but did not increase or decrease significantly.

Figure 3 summarizes the average SCA during each season in China from December 2000 to November 2014. The results indicate that over the past 14 years, the average SCA in China was approximately $27.0 \%$ during the winter, $10.7 \%$ during the spring, $6.8 \%$ during the fall, and $1.2 \%$ during the summer. The average SCA during the winter and summer decreased, and the average SCA in spring and fall increased.

\subsection{Snow-covered days}

Figure 4 shows the spatial distribution of the average annual number of SCDs from December 2000 to November 2014. The transient snow-covered regions with fewer than 10 annual SCDs were distributed primarily in east and south China, the Tarim Basin in Xinjiang, the Badain Jaran Desert in Inner Mongolia, and the Qaidam Basin in the Tibetan Plateau. The unstable snow-covered regions $(10<\mathrm{SCD} \leq 60)$ were primarily located to the north of the Hengduan, Qinling-Taihang, and Changbai Mountains in China, in the North China Plain, in some hilly areas in southeast China, and most regions in the northern and western parts of China. The relatively stable snow-covered regions $(60<\mathrm{SCD} \leq 350)$ were primarily located in northeast China-Inner Mongolia, north Xinjiang, and the high mountains of the Tibetan Plateau. Considering the accuracy of the MODIS snow product (Wang et al., 2015), we classified regions with more than 350 SCDs as permanent snowcovered regions; they were mainly located in the Tien Shan in Xinjiang, the Qilian, Kunlun, Nyainqêntanglha, and the Himalaya in the Tibetan Plateau.

The $\mathrm{M}-\mathrm{K}$ method was used to analyze the variation in the annual number of SCDs in China from December 2000 to November 2014 (Fig. 5). The number of SCDs in China has decreased by $29.2 \%$ over the past 14 years $(Z<0)$, for which $6.5 \%$ of the area decreased significantly $(p<0.05)$. These regions were primarily located in the Tien Shan in Xinjiang and most of the Tibetan Plateau. The regions with increasing numbers of SCDs represented $34.5 \%$ of China $(Z>0)$, of which $10.8 \%$ of the area increased significantly $(p<0.05)$. These regions were mainly located in the Great Khingan Mountains, Lesser Khingan Mountains, and Changbai Mountains in the northeastern part of the country, and most regions of south China.

The $\mathrm{M}-\mathrm{K}$ method was also used to analyze the variation in SCDs during the winter (December-February), spring (March-May), summer (June-August), and fall (SeptemberNovember) in the grid cells (Fig. 6). The results indicate that over the past 14 years, the regions with significantly decreased numbers of winter SCDs represented $5.7 \%$ of the area of China, whereas the areas with significant increases 

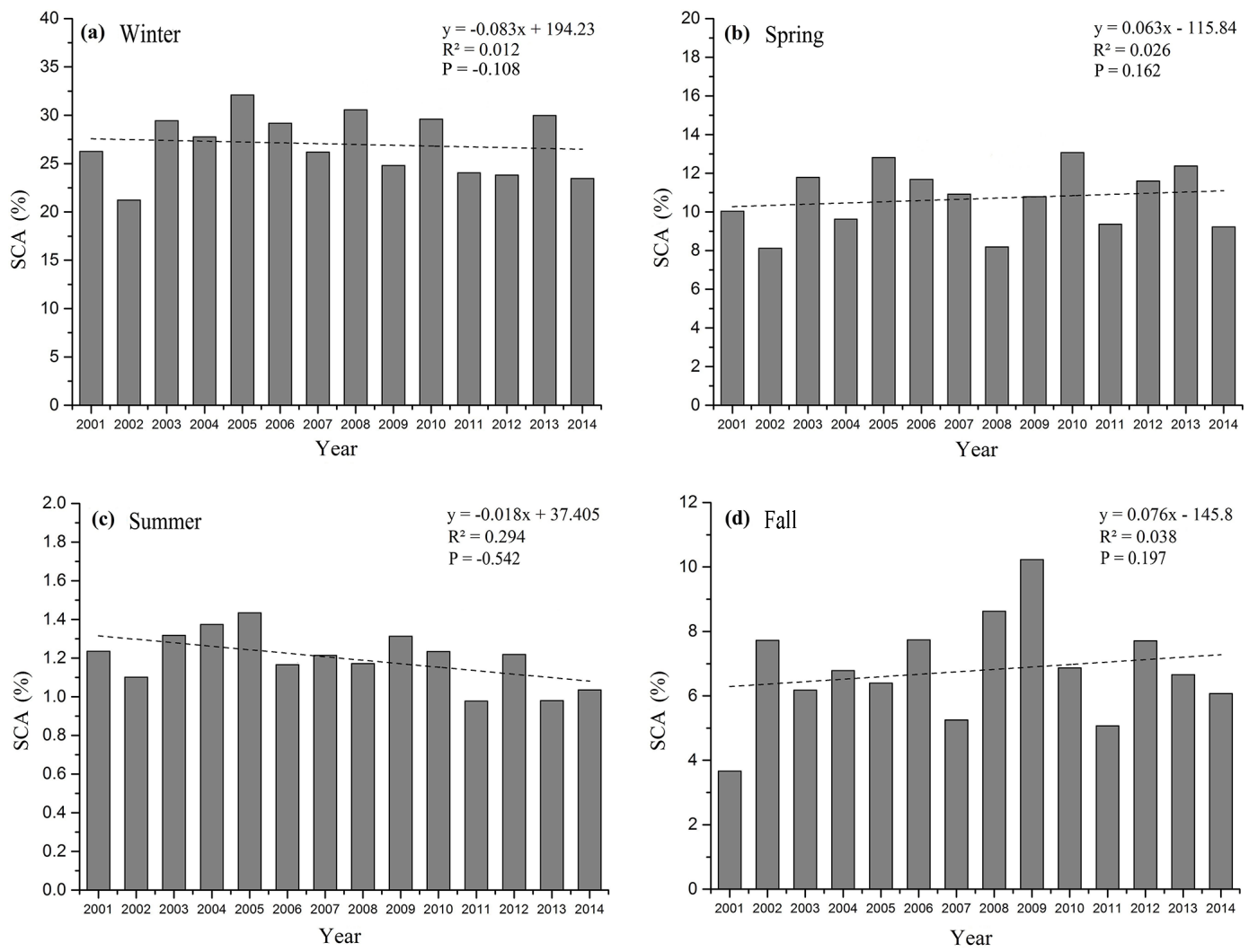

Figure 3. Histograms of the average SCA in each season in China from December 2000 to November 2014. Panels (a)-(d) show the average SCA in winter, spring, summer, and fall, respectively.

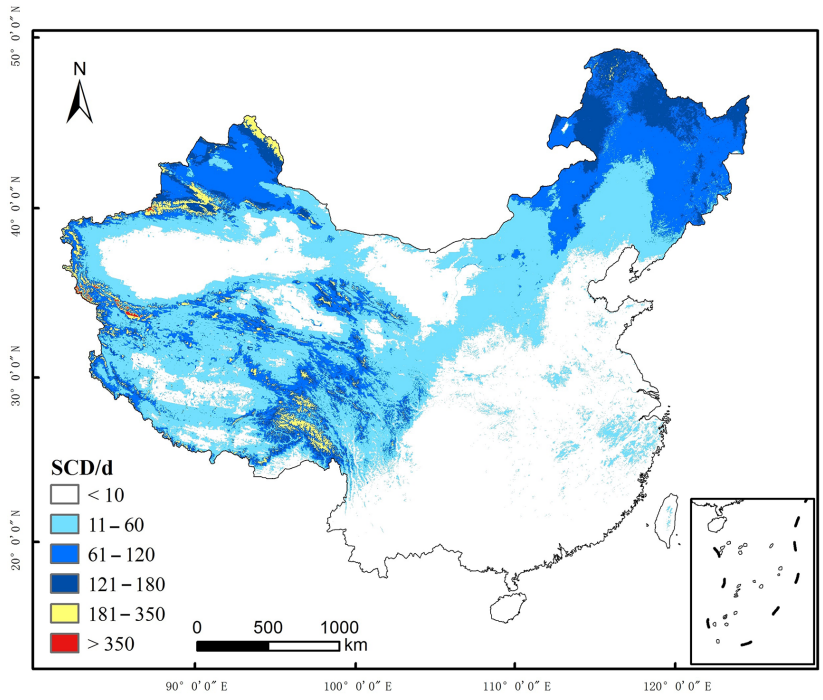

Figure 4. Spatial distribution of the average annual number of snow-covered days during 2001-2014 in China.

made up $7.2 \%$ of the study region (Fig. 6a). The regions with significantly decreased spring SCDs constituted $4.0 \%$ of China, whereas the regions with significant increases rep- resented $6.2 \%$ (Fig. 6b). The regions with significantly decreased summer SCDs made up $3 \%$ of China, whereas the regions with significant increases constituted $2.9 \%$ (Fig. 6c). The regions with significantly decreased fall SCDs constituted $1.8 \%$ of China, whereas the regions with significant increases constituted $5.7 \%$ (Fig. 6d). The results indicate that over the past 14 years, the summer SCDs decreased, whereas the SCDs during the winter, spring, and fall all increased. The spatial distributions of the increases and decreases in SCDs during each season were highly consistent. Specifically, the winter SCDs in south China increased, the SCDs in northeast China increased during all of the seasons, and the SCDs in the Xinjiang regions mainly decreased. The SCDs on the southwest margin of the Tibetan Plateau and the southeast region increased, whereas those in the north and northwest mainly decreased.

The results of the $\mathrm{M}-\mathrm{K}$ variation analysis show that the annual number of SCDs in south China increased significantly. To further analyze the trend of the SCDs in China over the past 14 years, we calculated the slope of the variation in the annual SCDs using Sen's median method (Fig. 7). The results indicate that the annual number of SCDs decreased over approximately $22.1 \%$ of China $(\beta<0)$, and increased over $23.5 \%$ of China $(\beta>0)$. The rate of decrease in the annual SCDs was less than 2 day $\mathrm{yr}^{-1}$ over $18.5 \%$ of the 

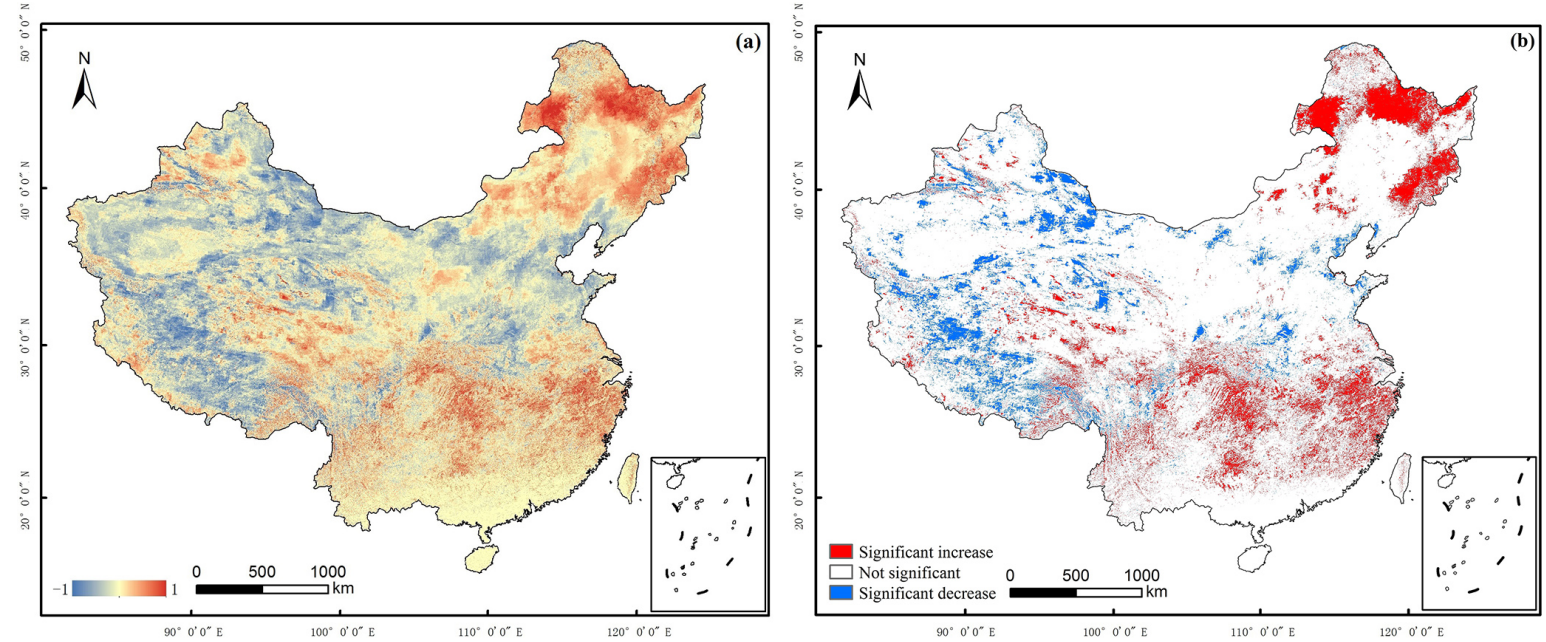

Figure 5. Variation in the average annual SCDs in China based on the Mann-Kendall method from 2001 to 2014. (a) Variation in the annual SCDs; (b) significance of the variation in the annual SCDs.
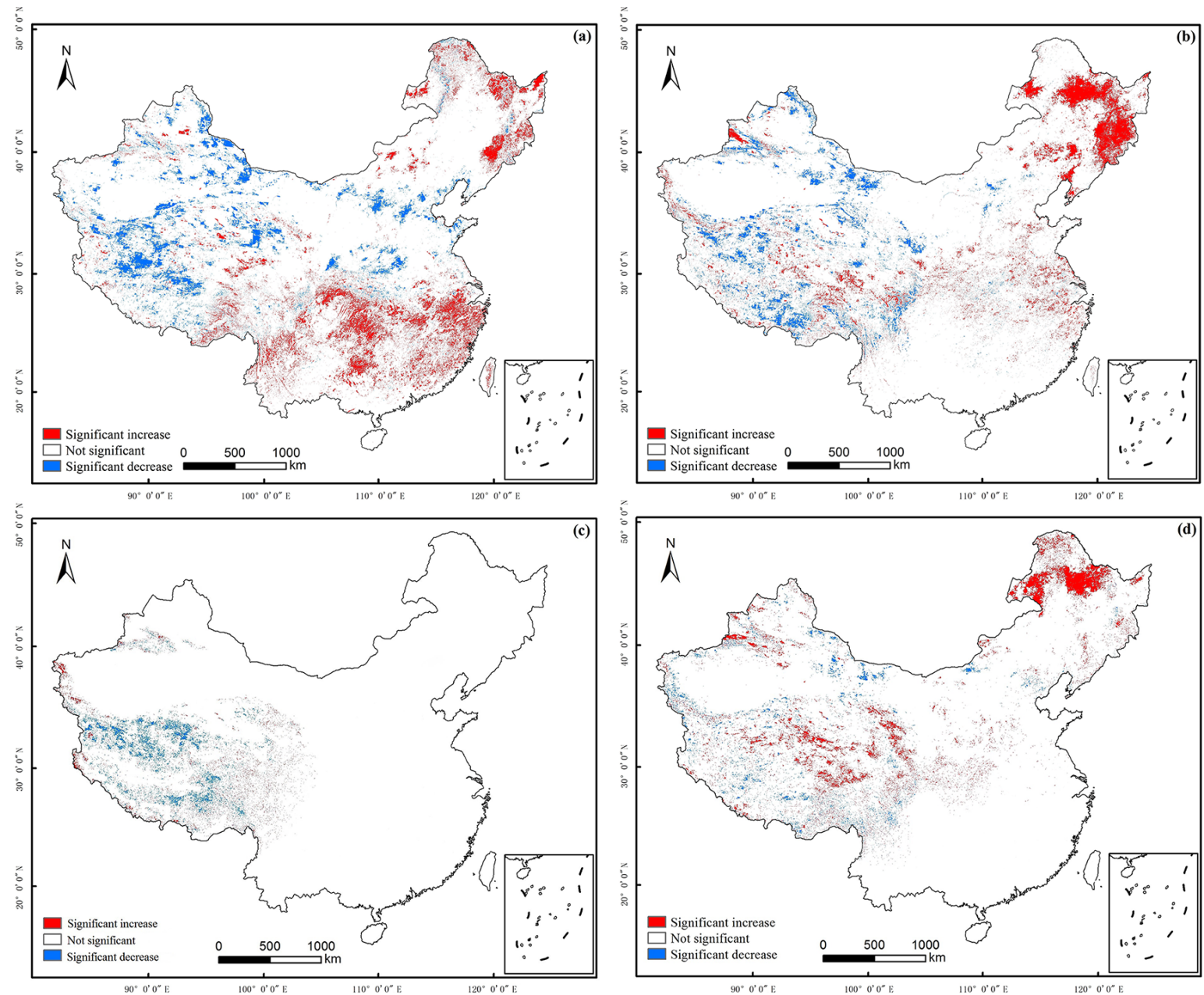

Figure 6. Variation in the number of SCDs during each season in China based on the Mann-Kendall method from 2001 to 2014 . Panels (a)-(d) show the significance of the variation in the number of SCDs during the winter, spring, summer, and fall, respectively. 


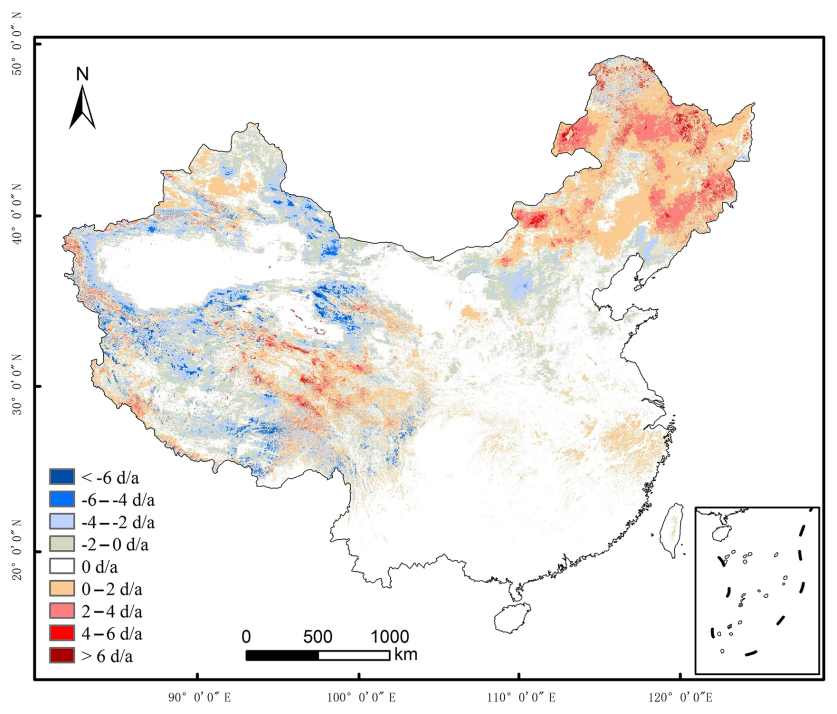

Figure 7. Variation slope of the average annual number of SCD in China based on Sen's median method during the period of 20012014.

area, which was sparsely distributed in Xinjiang, the Tibetan Plateau, and north China. The rate of decrease in some regions of the Tibetan Plateau exceeded 6 day $\mathrm{yr}^{-1}$. The rate

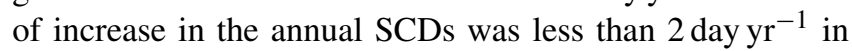
$18.3 \%$ of the area, which was mainly distributed in south China, northeast China, central northern Xinjiang, and the southeast Tibetan Plateau. The regions with rates of increase of more than 6 day $\mathrm{yr}^{-1}$ were sparsely distributed in northeast China and the southeast Tibetan Plateau. The results from Sen's median method were highly consistent with the results from the Mann-Kendall method, especially in terms of the spatial distribution of the variations. Because the regions in southeast China were mainly transient snow-covered regions, and the main relatively stable snow-covered regions were located in northern Xinjiang, in northeast China, and the Tibetan Plateau, the variation in the number of SCDs indicates that the annual SCDs in China increased overall (Figs. 5 and 7). However, the decreases in the SCDs in the Tibetan Plateau and the Tien Shan in Xinjiang, which have high elevations, were significant.

\subsection{Snow depth}

SD is a key factor that reflects the variation of the surface snow cover and has important hydrological, climate, and ecological significance. Figure 8 shows the spatial distribution of the average SD from December 2000 to November 2014. The average SD was calculated by dividing the sum of the SD by the total number of days. The spatial distributions of the average SD and SCDs in China were highly consistent. The regions with high values of the average SD were mainly distributed in the Great Khingan Mountains and Lesser Khingan Mountains in northeast China, the Tien Shan and Altai

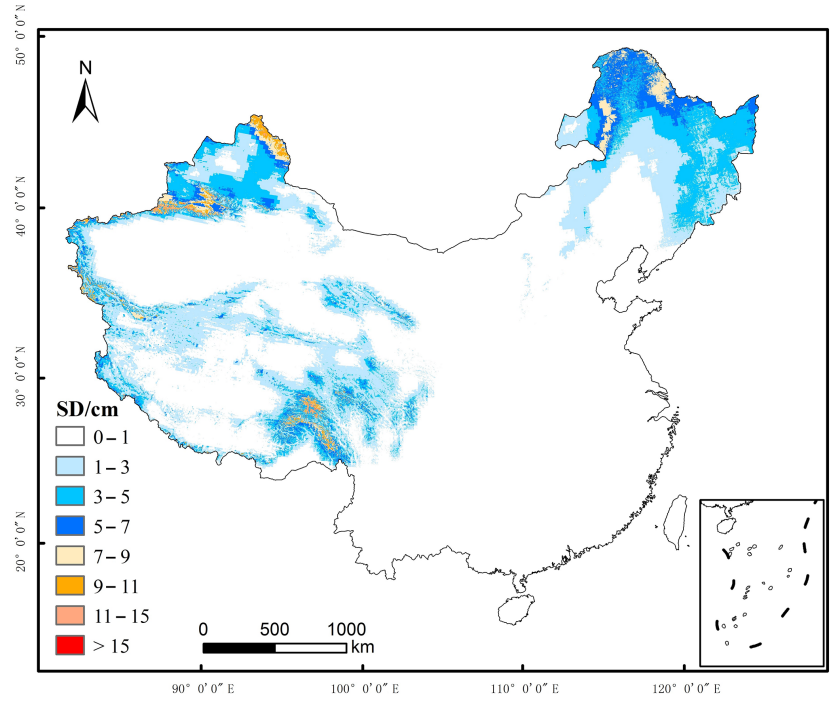

Figure 8. Spatial distribution of the average annual snow depth in China from December 2000 to November 2014.

Mountains in Xinjiang, and the Kunlun and Nyainqêntanglha Mountains in the Tibetan Plateau. The multi-year average SD was greater than $7 \mathrm{~cm}$. Except for the Tibetan Plateau, the SD generally increased with increasing latitude and elevation. However, because of the limited capability of passive microwave data to detect shallow snow and wet snow, the data did not capture any snowfall information in most regions in south China. Therefore, it is necessary to combine optical and passive microwave data to improve the accuracy of snow cover monitoring.

Figure 9 summarizes the spatial variation of the average annual SD in China from December 2000 to November 2014. The variations in the SD and the SCDs were highly spatially consistent. The regions with decreasing average annual SD covered $11 \%$ of China, and the average annual SD significantly decreased in $3.3 \%$ of the China $(p<0.05)$, primarily in most regions of north Xinjiang and the north Tibetan Plateau. A total of $22.4 \%$ of the area showed a tendency of increase, and significant increases were observed in $8.5 \%$ of the area $(p<0.05)$, which was mainly distributed in northeast China, the Tien Shan and Altai Mountains in Xinjiang, the south Tibetan Plateau, and the Kunlun Mountains.

Over the past 14 years, the regions with significantly decreased winter SD made up $10.6 \%$ of China, whereas the regions with significant increases constituted $9.3 \%$ (Fig. 10a). The regions with significantly decreased spring SD constituted $7.9 \%$ of the area of China, whereas the regions with significant increases made up $9.8 \%$ (Fig. 10b). The regions with significantly decreased summer SD made up $1.9 \%$ of China, whereas the regions with significant increases constituted $0.9 \%$ (Fig. 10c). The regions with significantly decreased fall SD represented $7.8 \%$ of the area of China, whereas the regions with significant increases only made up 

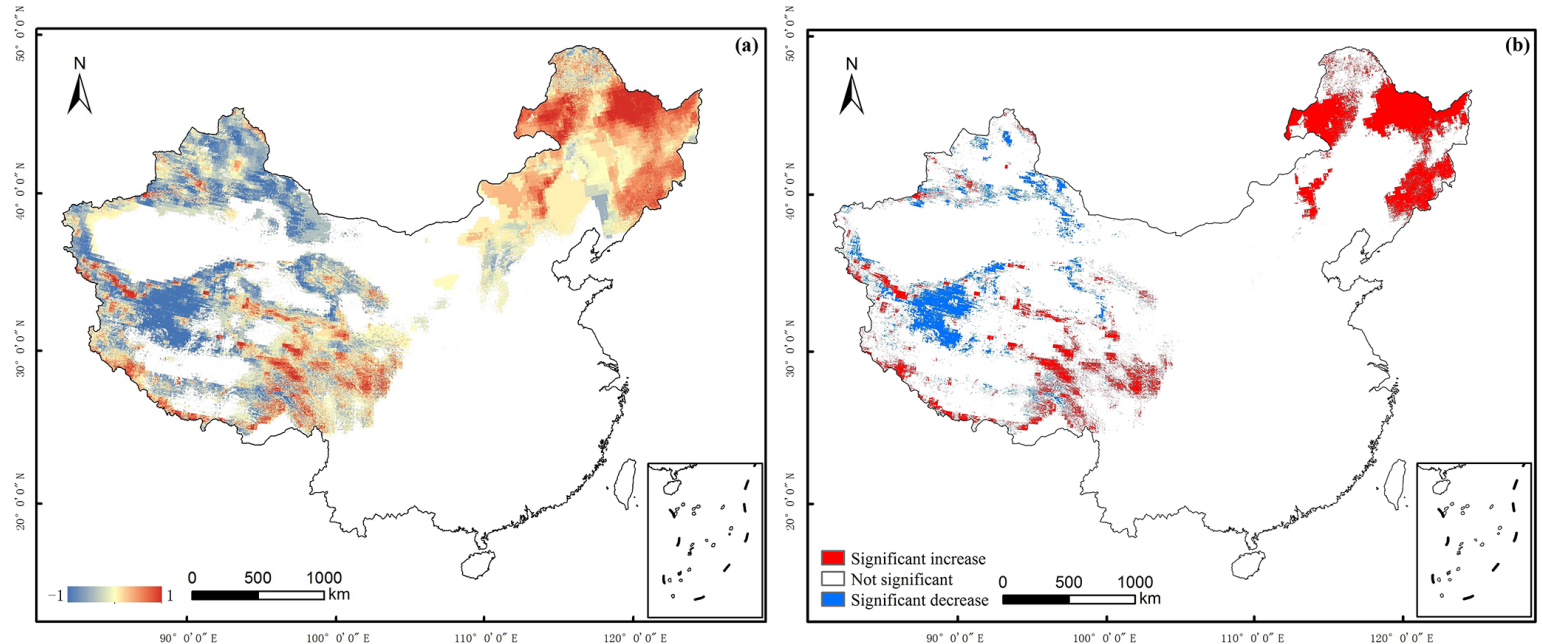

Figure 9. Variation in the average annual SD in China based on the Mann-Kendall method between 2001 and 2014. (a) Variation in the average annual SD; (b) significance of the variation in the average annual SD.
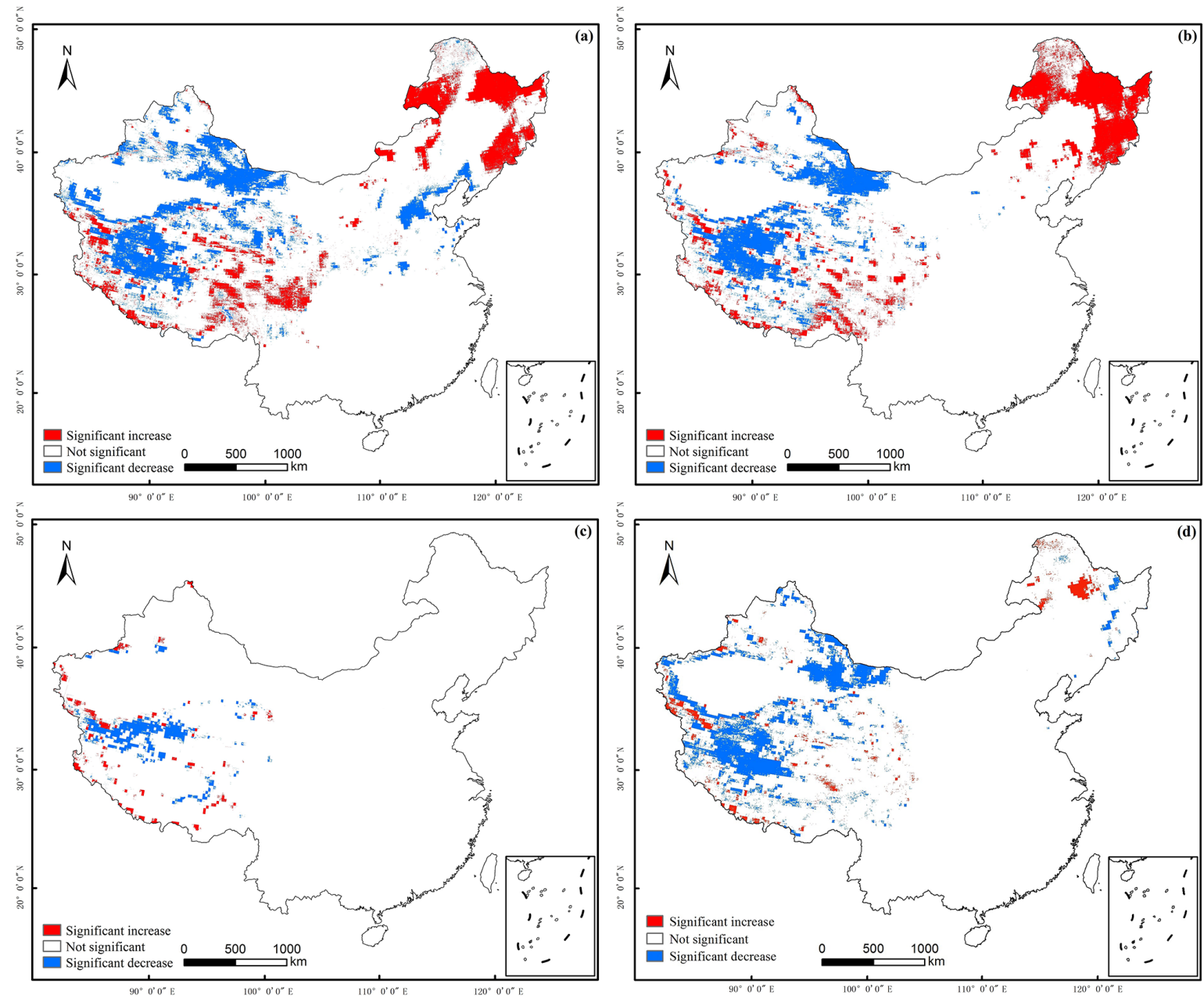

Figure 10. Variation in the average SD during each season in China based on the M-K method from 2001 to 2014. Panels (a)-(d) show the significance of the variations during the winter, spring, summer, and fall, respectively. 
$1.8 \%$ (Fig. 10d). The regions with significantly increased and decreased average SD during the winter and spring were similar. The regions with increased SD were mainly concentrated in northeast China and the high mountains of the Tibetan Plateau, whereas the regions with decreased SD were primarily located in the hinterlands of Xinjiang and the Tibetan Plateau. The SD during the fall and summer mainly decreased, and the regions with decreasing SD were mainly distributed in Xinjiang and the Tibetan Plateau.

\section{Discussion}

Snow cover is widely distributed in China. The results of this study indicate that the average annual SCA did not change significantly. The relative stable snow-covered regions $(60<\mathrm{SCD} \leq 350)$ in China were primarily located in northeast China-Inner Mongolia, north Xinjiang, and the high mountains in the Tibetan Plateau, and the stable snow area did not change significantly during 2001-2014. Liu et al. (2012) studied the spatial stability of the three major snow-covered regions in China for 2001-2010, and analyzed the characteristics of the seasonal and annual snow cover variations. The results indicated that the snow cover stabilities in the three major snow-covered regions were in the order of Xingjiang $>$ northeast China-Inner Mongolia $>$ Tibetan Plateau. The stable SCA in China did not change significantly. The same results were also found for the relatively stable snow-covered regions, whereas the unstable snowcovered regions (SCDs $<60$ ) had large annual variations in the SCA (Wang and Che, 2012). Dou et al. (2010) used the MODIS snow cover product to study the Tian Shan in China, and indicated that the snow cover in the Tian Shan increased slightly; the increase was especially significant in the winter. Furthermore, the snow cover decreased in the regions with elevations of $\geq 4000 \mathrm{~m}$ and increased in the regions with elevations of $<4000 \mathrm{~m}$. This study found similar results, but the significant increase in SCDs was observed in the spring, not in the winter.

Dai et al. (2010) indicated that the number of SCDs and the SD in China increased between 1978 and 2005. The western Tibetan Plateau was a sensitive region with an abnormal variation in SCDs, whereas northern Xinjiang, the mountainous regions in northeast China, and the east-central Tibetan Plateau were sensitive regions with abnormal SD variations. Che and $\mathrm{Li}$ (2005) used the SD data that were inverted from SSM/I passive microwave data to analyze the snow cover distribution and variations in China for 1993-2002. The results indicated that the snow cover reservoir in China did not increase or decrease significantly over that 10 -year period. The winter snow cover reservoir was mainly located in the three major stable snow-covered regions of Xinjiang, the Tibetan Plateau, and northeast China. The study by Yang et al. (2012) on the variation of snow cover in Tibet indicated that from 1980 to 2009, the SCDs and maximum SD in Tibet decreased. The decrease was very significant after the start of the 21 th century. The variations were slightly different in different seasons, and the results observed by different remotesensing satellites were also different. Our study showed that over the past 14 years, the SCDs and SD decreased primarily in the hinterlands of the Tibetan Plateau, and increased in the southwest and southeast margins of the Tibetan Plateau. Studies based on long time series of observations by ground stations have indicated that the number of SCDs and the SD in northeast China increased every year (Chen and Li, 2011; Yan et al., 2015; Ke et al., 2016), which is consistent with our results for northeast China over the past 14 years.

\section{Conclusion}

In this study, we used the daily cloudless snow cover and snow depth products, both at $500 \mathrm{~m}$ pixel size, to investigate the variations of the snow-covered area (SCA), snow-covered days (SCDs), and snow depth (SD) in China from December 2000 to November 2014. The important results are summarized below.

1. The perennial average annual SCA in China was $11.3 \%$ over the entire year and $27.0 \%$ during the winter for the period of 2001-2014. The average SCA decreased during the winter and summer, and increased during the spring and fall. The average annual SCA varied slightly, but did not increase or decrease significantly.

2. The transient snow cover in China was mainly located in east and southeast China and some regions of Xinjiang and Inner Mongolia, whereas the unstable snowcovered regions were distributed in most of the northern and western regions in China. The stable snow-covered regions were mainly located in northeast China-Inner Mongolia, north Xinjiang, and the Tibetan Plateau. The west Tien Shan in Xinjiang and the mountainous areas of the Tibetan Plateau were the main regions with permanent snow cover.

3. The summer SCDs in China decreased, whereas the SCDs increased during the winter, spring, and fall. Specifically, the winter SCDs in south China increased, the SCDs in northeast China increased during all of the seasons, and the SCDs in the Xinjiang regions mainly decreased. Overall, the SCDs increased during 20012014 in China.

4. The spatial distribution of the variation in the average SD was highly consistent with that of the SCDs. The spatial distributions of the amounts of increase and decrease in the snow cover during each season were also highly consistent. However, the regional differences in the increases in the average annual SCDs and average SD were significant. The regions with increasing SCDs and SD were mainly located in northeast China, 
whereas the Tibetan Plateau and Xinjiang were the main regions with decrease.

\section{Data availability}

- Long Time Series Snow Depth Dataset in China (1979-2014) (doi:10.3972/westdc.001.2015.db): Che et al. (2008), http://westdc.westgis.ac.cn/data/ df40346a-0202-4ed2-bb07-b65dfcda9368;

- MODIS/Terra Snow Cover Daily L3 Global 500 m Grid, Version 5: Hall et al. (2006), updated daily.

- MODIS/Terra Snow Cover Daily L3 Global $500 \mathrm{~m}$ Grid V005 (December 2000 to November 2014): Digital media, National Snow and Ice Data Center, http://nsidc.org/data/docs/daac/modis_v5/mod10a1_ modis_terra_snow_daily_global_500m_grid.gd.html;

- MODIS/Aqua Snow Cover Daily L3 Global 500 m Grid, Version 5: Hall et al. (2007), updated daily;

- MODIS/Aqua Snow Cover Daily L3 Global $500 \mathrm{~m}$ Grid V005 (December 2000 to November 2014): Digital media, Boulder, National Snow and Ice Data Center, Colorado, USA, http://nsidc.org/data/docs/daac/modis_v5/myd10a1_ modis_aqua_snow_daily_global_500m_grid.gd.html.

Acknowledgements. This work was supported by the China State Key Basic Research Project (2013CBA01802) and the Chinese Natural Science Foundation Projects (41671330, 31372367, and 41471291).

Edited by: T. Zhang

Reviewed by: two anonymous referees

\section{References}

Bai, S., Wu, Q., Shi, J., and Gu, H.: Relationship between the spatial and temporal distribution of snow depth and the terrain over the Tibetan Plateau, Remote Sens. Land Res., 27, 171-178, 2015.

Basang, Y., Lazhen, X., Zheng, Z., Kuangda, and Laba: Variation of snow cover Tibet autonomous region based on multi-source data, J. Glaciol. Geocryol., 34, 1023-1030, 2012.

Bloch, M. R.: Dust-induced albedo changes of polar ice sheets and glacierization, J. Glaciol., 5, 241-244, 1964.

Che, T. and Li, X.: Spatial distribution and temporal variation of snow water resources in China during 1993-2002, J. Glaciol. Geocryol., 27, 64-67, 2005.

Che, T., Li, X., Jin, R., Armstrong, R., and Zhang, T. J.: Snow depth derived from passive microwave remote-sensing data in China, Ann. Glaciol., 49, 145-154, 2008.
Che, T., Dai, L. Y., Zheng, X. M., Li, X. F., and Zhao, K.: Estimation of snow depth from MWRI and AMSR-E data in forest regions of Northeast China, Remote Sens. Environ., 183, 334-349, 2016.

Chen, G. and Li, D.: Temporal-spatial characteristics of cumulative snow depth in Northeast China and its vicinity, Meteorol. Mon., 37, 513-521, 2011.

Chen, M.: Spatio-temporal change dynamic of snowline on Tibetan Plateau, Lanzhou University, Lanzhou, 2014.

Chen, Q.: The snow disaster and its defence strategy in Yushu Tibetan prefecture of Qinghai Province, Pratacult. Sci., 13, 60-63, 1996.

Chen, Q. and Liu, Y.: Studies on relationships among snow cover winter over the Tibetan plateau and droughts/floods during Meiyu season in the middle and lower reaches of the Yangtze river as well as atmosphere/ocean, Acta Meteorol Sin., 58, 582595, 2000.

Chen, X., Zeng, Q., and Lan, Y.: Satellite snow cover monitoring and snowmelt runoff prediction in the high alpine area of northwestern China, Proceedings of an international symposium held during the 20th general assembly of the international union of geodesy and geophysics at Vienna, 161-168, 1991.

Dai, L., Che, T., and Ding, Y.: Inter-Calibrating SMMR, SSM/I and SSMI/S Data to Improve the Consistency of Snow-Depth Products in China, Remote Sens., 7, 7212-7230, 2015.

Dai, L. Y., Che, T., Wang, J., and Zhang, P.: Snow depth and snow water equivalent estimation from AMSR-E data based on a priori snow characteristics in Xinjiang, China, Remote Sens. Environ., 127, 14-29, 2012.

Dai, S., Zhang, B., Cheng, F., Wang, H., and Wang, P.: The spatiotemporal variations of snow cover in China from the snow depth time series dataset based on passive microwave remote sensing, J. Glaciol. Geocryol., 32, 1066-1073, 2010.

Dou, Y., Chen, X., Bao, A. M., and Li, L.: Study of the temporal and spatial distribute of the snow cover in the Tianshan Mountains, China, J. Glaciol. Geocryol., 32, 28-34, 2010.

Gao, M., Qin, Z., and Xu, B.: Integration of remote sensing with GIS for grassland snow cover monitoring and snow disaster evaluating in Tibet, Proc. SPIE 7110, Remote Sensing for Environmental Monitoring, GIS Applications, and Geology VIII, 711000 (13 October 2008); doi:10.1117/12.800047, 2008.

Hahn, D. G. and Shukla, J.: An apparent relationship between Eurasian snow cover and Indian monsoon rainfall, J. Atmos. Sci., 33, 2461-2462, 1976.

Hall, D. K., Riggs, G. A., Salomonson, V. V., Digirolamo, N. E., and Bayr, K. J.: MODIS snow-cover products, Remote Sens. Environ., 83, 181-194, 2002.

Helsel, D. R. and Hirsch, R. M.: Statistical methods in water resource, Elsevier, Science Publishers, Amsterdam, the Netherlands, 1992.

Huang, X. D., Hao, X. H., Wang, W., Feng, Q. S., and Liang, T. G.: Algorithms for cloud removal in MODIS daily snow products, J. Glaciol. Geocryol., 34, 1118-1126, 2012.

IPCC: Climate change 2013: the physical science basis [M/OL], Cambridge University Press, Cambridge, http://www.ipcc.ch/ report/ar5/wg1/\#.UqtD7KBRRI, last access: 30 September 2013.

Ke, C.-Q., Li, X.-C., Xie, H., Ma, D.-H., Liu, X., and Kou, C.: Variability in snow cover phenology in China from 1952 to 2010, Hydrol. Earth Syst. Sci., 20, 755-770, doi:10.5194/hess-20-7552016, 2016. 
Kongoli, C., Romanov, P., and Ferraro, R.: Snow cover monitoring from remote sensing observations - possibilities for drought assessment, in: Remote Sensing and Drought - New and Emerging Monitoring Approaches, chap. 15, 1st Edn., edited by: Wardlow, B. D., Anderson, M. C., and Verdin, J. P., CRC Press Taylor and Francis Group, 359-386, 2012.

Lee, W. S., Bhawar, R. L., Kim, M. K., and Sang, J.: Study of aerosol effect on accelerated snow melting over the Tibetan Plateau during boreal spring, Atmos. Environ., 75, 113-122, 2013.

Li, P. J.: Response of Xinjiang snow cover to climate change, Acta Meteorol. Sin., 59, 491-501, 2001.

Li, P. J.: Distribution of snow cover in China, J. Glaciol. Geocryol., $5,9-17,1983$.

Liang, T. G., Wu, C. X., Chen, Q. G., and Xu, Z. B.: Snow Classification and Monitoring Models in the Pastoral Areas of the Northern Xinjiang, J. Glaciol. Geocryol., 26, 160-165, 2004.

Liu, J., Chen, R., and Song, Y.: Distribution and variation of snow cover in China, Adv. Clim. Change Res., 8, 364-371, 2012.

Liu, X., Liang, T. G., and Guo, Z. G.: Early warning and risk assessment of snow disaster in pastoral area of northern Xinjiang, Chin. J. Appl. Ecol., 19, 133-138, 2008.

Liu, X., Zhang, J., Tong, Z., Bao, Y., and Zhang, D.: Grid-based multi-attribute risk assessment of snow disasters in the grasslands of Xilingol, Inner Mongolia, Hum. Ecol. Risk Assess., 17, 712$731,2011$.

McBean, E. and Motiee, H.: Assessment of impact of climate change on water resources: a long term analysis of the Great Lakes of North America, Hydrol. Earth Syst. Sci., 12, 239-255, doi:10.5194/hess-12-239-2008, 2008.

Mhawej, M., Faour, G., Fayad, A., and Shaban, A.: Towards an enhanced method to map snow cover areas and derive snow-water equivalent in Lebanon, J. Hydrol., 513, 274-282, 2014.

Nolin, A. W. and Stroeve, J. C.: The changing albedo of the Greenland ice sheet: implications for climate modeling, Ann. Glaciol., 25, 51-57, 1997.

Pei, H., Qin, Z., Fang, S., and Liu, Z.: Snow mapping for water resource management using MODIS satellite data in northern Xinjiang, China, Proc. SPIE 7140, Remote Sensing for Agriculture, Ecosystems, and Hydrology X, 710414 (2 October 2008), doi:10.1117/12.800203, 2008.

Pulliainen, J.: Mapping of snow water equivalent and snow depth in boreal and sub-arctic zones by assimilating space-borne microwave radiometer data and ground-based observations, Remote Sens. Environ., 101, 257-269, 2006.

Qian, Y. F., Zheng, Y. Q., Zhang, Y., and Miao, M. Q.: Responses of China's summer monsoon climate to snow anomaly over the Tibetan Plateau, Int. J. Climatol., 23, 593-613, 2003.
Robinson, D. A.: Hemispheric snow cover and surface albedo for model validation, Ann. Glaciol., 25, 241-245, 1997.

Seidel, K. and Martinec, J.: Remote Sensing in Snow Hydrology, Runoff Modelling, Effect of Climate Change, Springer-Praxis, Springer, Berlin, 2004.

Shen, Y. P., Su, H. C., Wang, G. Y., Mao, W. F., Wang, S. D., Han, P., Wang, N. L., and Li, Z. Q.: The responses of glaciers and snow cover to climate change in Xinjiang (I): hydrological effects, J. Glaciol. Geocryol., 35, 513-527, 2013.

Wang, C. H., Wang, Z. L., and Cui, Y.: Snow cover of China during the last 40 years: spatial distribution and interannual variation, $\mathbf{J}$ Glaciol. Geocryol., 31, 301-310, 2009.

Wang, J., Li, H., Hao, X., Huang, X., Hou, J., Che, T., Dai, L., Liang, T., Huang, C., Li, H., Tang, Z., and Wang, Z.: Remote sensing for snow hydrology in China: challenges and perspectives, J. Appl. Remote Sens., 8, 4480-4494, 2014.

Wang, W., Huang, X., Deng, J., Xie, H., and Liang, T.: Spatiotemporal change of snow cover and its response to climate over the Tibetan Plateau based on an improved daily cloud-free snow cover product, Remote Sens., 7, 169-194, 2015.

Wang, Z. and Che, T.: Spatiotemporal distribution of snow cover in arid regions in China, Cold Arid Reg., 29, 464-471, 2012.

Wang, Z. L., Wang, X. P., and Li, Y. H.: Analyses of Snow Cover Based on Passive Microwave Remote Sensing Data and Observed Data over the Tibetan Plateau, J. Glaciol. Geocryol., 35, 783-792, 2013.

Wang, W., Liang, T., Huang, X., Feng, Q., Xie, H., Liu, X., Chen, M., and Wang, X.: Early warning of snow-caused disasters in pastoral areas on the Tibetan Plateau, Nat. Hazards Earth Syst Sci., 13, 1411-1425, doi:10.5194/nhess-13-1411-2013, 2013.

Yan, S., Zhao, C., Gou, X., and Wang, Y.: Spatial distributions and variations of the snow cover in the forests of Northeast China, J. Arid Land Res. Environ., 29, 154-162, 2015.

Yao, T., Thompson, L., Yang, W., Yu, W., Gao, Y., Guo, X., Yang, X., Duan, K., Zhao, H., Xu, B., Pu, J., Lu, A., Xiang, Y., Kattel, D., and Joswiak, D.: Different glacier status with atmospheric circulations in Tibetan Plateau and surroundings, Nat. Clim. Change, 2, 663-667, 2012.

Zhang, Y., Li, B., and Zhang, D. A.: Discussion on the boundary and area of the Tibetan Plateau in China, Geogr. Res., 21, 1-8, 2002.

Zhao, P., Zhou, Z. J., and Liu, J. P.: Variability of the Tibetan spring snow and its associations with the hemispheric extropical circulation and East Asian summer monsoon rainfall: An observational investigation, J. Climate, 20, 3942-3955, 2007. 